\title{
A TREATMENT OF UNDESCENDED TESTICLE IN INFANCY*
}

\author{
BY \\ C. G. SCORER \\ From Hillingdon Hospital, Uxbridge
}

This study is based upon the examination of 2,700 newborn boys. The original purpose was to find out how often the testicle was undescended at birth and what happened in such cases during the first few months of life.

It is not difficult to feel the testicle of a newborn boy if it be lying outside the external inguinal ring. Examination may only become uncertain, and at times impossible, when the natural increase of subcutaneous fat and the activity of the cremaster muscle combine to conceal the organ in the groin. These events, however, do not occur until the age of 6 months or more and even then are usually insufficient to cast doubt on the findings.

Because the testicle can be felt in the scrotum at birth it is possible to measure its distance from the pubic crest with reasonable accuracy. By so measuring, a standard can be established by which to judge whether descent has, or has not, taken place. The suggested figure in this investigation is $4 \mathrm{~cm}$. ( $1 \frac{1}{2}$ in.): at this point the testicle can lie comfortably in the scrotum.

This standard represents a minimum distance in a full-term infant ( $5 \mathrm{lb} .8 \mathrm{oz}$. or more) and it continues to be valuable for many years. It is normally found that in both infants and boys up to puberty the testicle lies between $4 \mathrm{~cm}$. and $8 \mathrm{~cm}$. from the pubic crest, depending largely on the degree of scrotal contraction. In adolescence, owing to increase in size of both testicle and scrotum, the normal distance is greater.

\section{Cases Investigated}

In this series 2,700 boys have been examined in the maternity department of a general hospital. Where one or both testicles was found to be incompletely descended a follow-up was continued for at least one year and in most cases much longer.

One hundred and eight boys were found to have the deformity (see table). Of these, the testicle was

* A paper read at the meeting of the British Association of Paediatric Surgeons in Edinburgh in June, 1957. observed to descend in 89 during the first 12 months of life, almost exactly two-thirds (60) during the first month. Of the remaining 19, in five the testicles did not appear to have changed position (they were small and at the external ring), three had never been felt and were presumably within the inguinal canal or abdomen, and 11 persisted just outside the top of the scrotum.

\section{The Obstructed Testicle}

It is with this latter group of 11 that curiosity was aroused. Why was there no advance into the scrotum? There were three distinctive features about these cases. First, the testicle was present at

\section{FOLLOW-UP OF 108 CASES}

Descended in one month ..

Descended between 2nd and 12th month

No advance since birth

Descent apparently obstructed :.

Never felt .

$\begin{array}{rrrr}. & \ldots & \ldots & 60 \\ . & \ldots & \ldots & 29 \\ . & \ldots & \ldots & 5 \\ . & \ldots & \ldots & 11 \\ & & \\ & \text { Total } & \ldots & \\ \end{array}$

birth or appeared within the first few days of life. Second, it was of good size and firm consistency, and third, it did not alter in position during many subsequent weeks or months of observation; it remained at the pubic crest or, at most, could be pushed 1 to $2 \mathrm{~cm}$. below it. Any attempt to push or pull it into the scrotum was unavailing.

On three or four occasions these infants produced a herniation into the unclosed processus vaginalis during the first three months. In treating the hernias by surgical excision of the sac, I was interested to find that the pathway from the external ring to the scrotum was blocked by a definite septum, or fibrous barrier, which had to be broken through by firm pressure before the scrotal cavity could be reached (Fig. 1). This septum lies at the junction of the smooth inguinal and corrugated scrotal skin. It forms the bottom of the 'superficial inguinal pouch'. Browne (1938) described it as 'an abnormal attachment of the fascia of Scarpa to the pubic bone'. He went on to say, 'This means that instead of the in- 
guinal pouch having an open lower end, the way from it into the scrotum is blocked by a strong fibrous hammock in which the testis lies supported.'

If these observations be correct it is clear that the

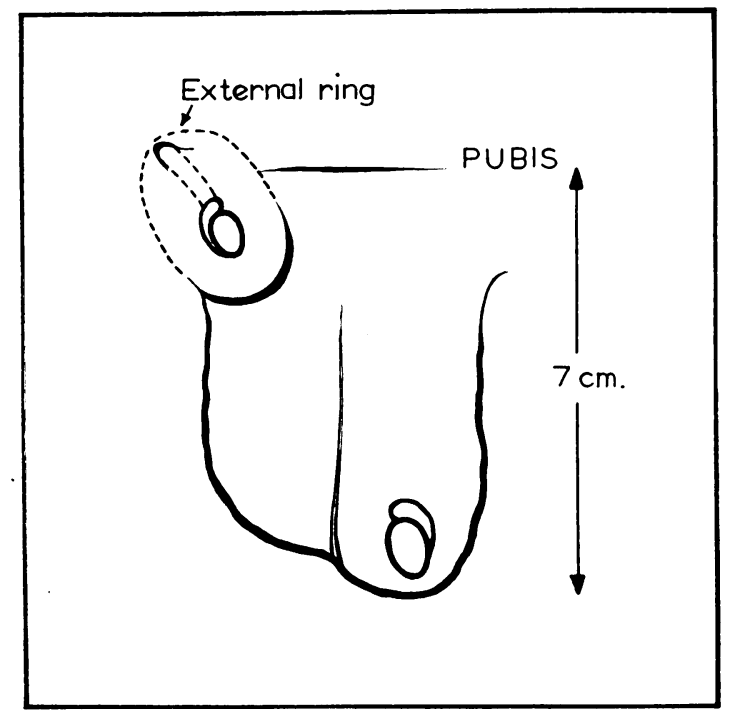

FIG. 1.-Diagram to represent the superficial inguinal pouch closed at its lower end.

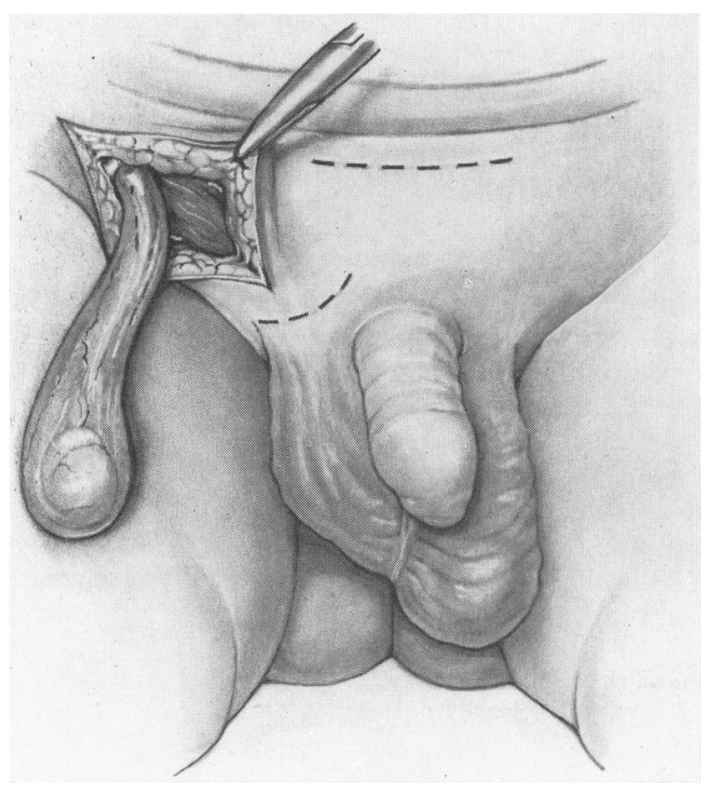

FIG. 2.-Testicle and cord dissected free. Interrupted lines represent levels of pubic crest and septum. Note smaller size of scrotum on the affected side. cause of failure of descent is an obstruction and is not inherent in a deformity of the testicle or a shortness of the cord. The rational treatment is therefore to remove the obstruction at an early age to enable the testicle to descend spontaneously or to place the organ in its normal position. The policy of waiting and the subsequent use of hormones is unlikely ever to be rewarded.

\section{A Surgical Treatment}

Operation was undertaken in 11 cases and the results have been reasonably satisfactory.

The technique is simple. By an incision over the external ring the superficial inguinal pouch is entered. The testicle and cord with their coverings are dissected clear (Fig. 2). The tunica vaginalis is opened and explored with a probe to find out if it communicates with the peritoneal cavity. If a hernia be present the sac is dissected off the cord and ligated as high as possible.

The lower end of the superficial inguinal pouch is then broken through with firm pressure by the little finger (Fig. 3). A stitch of nylon is passed through the gubernaculam, which at this age is a thick and strong structure attached to the lower pole of the testicle. Both ends of the nylon are threaded into the inguinal incision and out through the bottom of the scrotum, thus drawing the testicle down towards its normal position. After closing the inguinal wound the stitch is attached to the skin half-way

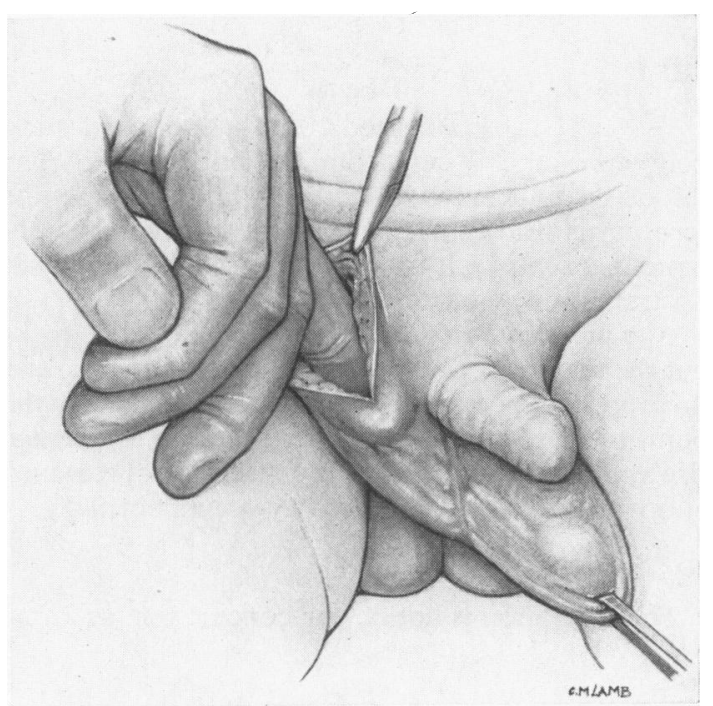

FIG. 3.-Septum about to be broken through with the little finger. 
down the inner side of the thigh (Fig. 4). In one case where this stitch was not used, the testis, encouraged by the application of napkins, slipped back into the groin after operation, and became fixed in that position. The stitch is kept in for two or possibly three days and tight napkins are not allowed for several days.

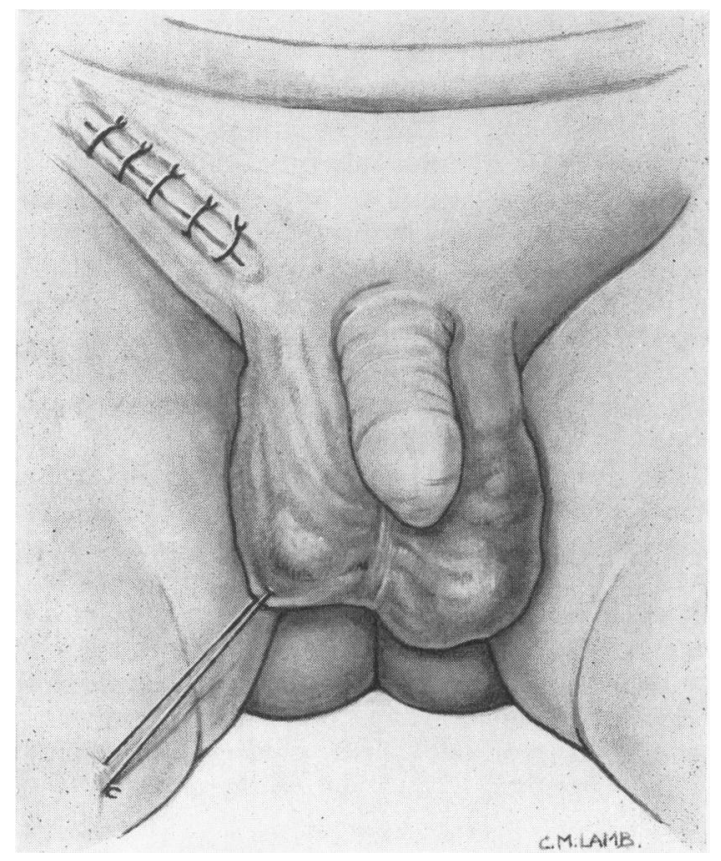

FIG. 4.-Nylon stitch holding the testicle in the scrotum.

\section{Results}

In the 11 infants treated 10 now have the testicle between 5 and $7 \mathrm{~cm}$. from the pubic crest. The testicle cannot always descend fully because the scrotum is often smaller on the side where the obstructing septum is found. In one of the cases obstruction was bilateral.

Age at operation varied between 3 and 52 weeks but the majority of infants were under 3 months, and this appears to be the most satisfactory time from the point of view of results. The testicle is of average size and firm. The cremaster muscle is not removed at operation so retractile activity occurs normally.

\section{Discussion}

This operation is not new in concept but, as far as
I know, has not been advised before as a definitive treatment in infants. It may well be criticized for three reasons.

Is it right to do inessential surgery in an infant? With modern anaesthesia and care the risk of surgery is evidently no greater than in the adult. Hospital admission is only necessary for two to three days and feeding is interfered with to the extent of missing only one meal.

Is it not probable that the testicle would descend if left alone? This group of cases of undescended testicle appears to correspond to what Browne calls 'superficial inguinal ectopia', for which he says operation is essential. In addition there is some evidence that if the testicle does not descend during the first few months of life it is unlikely ever to do so (Scorer, 1955).

Is there not a danger of injuring delicate structures? All surgical procedures can be dangerous or cause damage unless properly carried out. In some respects an infant's tissues are easier to handle than a boy's.

In favour of the operation is correction of a congenital deformity early in life. It is not yet known at what age spermatogenesis becomes permanently limited in the retained testicle but it may at least be impaired if the testicle is allowed to remain in the groin during boyhood. Moreover, in infants with undescended testicles a hernia is much better treated surgically than with a truss; six of the 11 cases had hernias and in two of the others a sac was not sought.

There seems to be, therefore, some rational grounds for considering the possibility of treating by surgery those infants in whom a failure of testicular descent is due to obstruction.

\section{Summary}

In the examination of 2,700 newborn infants, 18 cases were found in which one or both testicles did not descend into the scrotum during the first year of life. Of these, 11 appeared to have an obstruction to descent.

A simple operation is described to break through the obstruction and bring the testicle into the scrotum.

The value of the operation is critically discussed.

\section{REFFRENCES}

Browne, D. (1938) Brit, med J., 2, 168.

Scorer, C. G. (1955). Brit. J. Urol., 27, 374. 